\title{
ANALYSIS OF RELATIONSHIPS BETWEEN DIFFERENT TRAINING LOAD MONITORING TOOLS IN ELITE U-20 SOCCER
}

original paper

( ) University School of Physical Education in Wroclaw

DOI: https://doi.org/10.5114/hm.2018.81014

\section{GUILHERME DE SOUSA PINHEIRO ${ }^{1}$, ROBERTO CHIARI QUINTAO²,} IGOR CUSTODIO $^{2}$, DAVID CASAMICHANA ${ }^{3}$, BRUNO PENA COUTO ${ }^{2}$

${ }^{1}$ University of Kassel, Kassel, Germany

${ }^{2}$ Federal University of Minas Gerais, Belo Horizonte, Brazil

${ }^{3}$ University of the Basque Country, Vitoria-Gasteiz, Spain

\section{ABSTRACT}

Purpose. The study analysed the responses from different training load monitoring tools in the elite U-20 soccer category and checked the level of association between these responses.

Methods. The participants were 10 elite male soccer players (age, $18.61 \pm 0.95$ years; height, $176.81 \pm 5.03 \mathrm{~cm}$; body mass, $70.32 \pm 8.41 \mathrm{~kg}$ ). The progressive test to exhaustion assessed maximum oxygen consumption and maximum heart rate. The athletes were monitored over 15 training sessions with a heart-rate-based method (Edwards) and mechanical load indicators obtained from GPS devices (15 Hz).

Results. Individual training load was calculated with the Foster's session rating of perceived exertion (session-RPE) procedure. A significant correlation was found between session-RPE and Edwards $(0.564, p<0.05)$. There were no significant correlations between session-RPE and average speed (-0.161), average heart rate of the training session $(-0.187)$, distance over $20 \mathrm{~km} / \mathrm{h}(0.006)$, or number of accelerations performed in different zones $(-0.194,-0.178,-0.171,-0.236)$. The Edwards method showed significant correlations with the total distance $(0.642, p<0.01)$, average heart rate $(0.333, p<0.01)$, and distances covered at $0-20 \mathrm{~km} / \mathrm{h}(0.634, p<0.01 ; 0.568, p<0.01 ; 0.424, p<0.01 ; 0.289, p<0.01 ; 0.201, p<0.015)$. There were no significant correlations between Edwards and average speed (0.158), distance over $20 \mathrm{~km} / \mathrm{h}(0.014)$, number of accelerations performed in different zones $(-0.194,-0.178,-0.171,-0.236)$, or number of normalized accelerations $(-0.118,-0.038$, $-0.058,-0.035)$.

Conclusions. The Edwards method and session-RPE are limited load monitoring tools to indicate the reality of training situations (high-intensity action with recovery intervals).

Key words: GPS technology, training control, session-RPE

\section{Introduction}

To achieve a high level of athletic performance, it is necessary to subject the individual to stringent training situations, through a cyclic process of training-fatigue-adaptation [1]. In order to maximize the physical capabilities, training should be carefully planned, monitored, and adjusted. The systematization of training goes through an efficient distribution of the training load with adequate recovery [2, 3]. When this process is successful, there are positive adaptations to training, with consequent improvement in performance [4-6]. However, if the balance of training load and recovery is not achieved owing to application of excessive loads or to poor recovery, the athlete can adapt negatively, with the occurrence of overreaching and overtraining $[5,7]$.

Soccer is a sport in which success depends on physical, psychological, technical, and tactical factors [8]. In this discipline, the application of a specific training program can result in individual different responses among players [9]. A challenge for coaches is to determine the moment that the training may become in-

Correspondence address: Guilherme de Sousa Pinheiro, School of Physical Education, Physiotherapy and Occupational Therapy, Federal University of Minas Gerais - Load Evaluation Laboratory (LAC/EEFFTO-UFMG), Av. Presidente Antônio Carlos, 6627, Pampulha - Belo Horizonte - MG, CEP: 31.270-901, Brazil, e-mail: guilherme.gsp11@hotmail.com

Received: September 25, 2018

Accepted for publication: November 14, 2018

Citation: Pinheiro GS, Quintao RC, Custodio I, Casamichana D, Couto BP. Analysis of relationships between different training load monitoring tools in elite U-20 soccer. Hum Mov. 2018;19(5)special/issue:52-59; doi: https://doi.org/10.5114/hm.2018.81014. 
adequate for each athlete and perform the necessary adjustments, which are the respective objectives of monitoring [5] and load regulation [10, 11].

Heart rate (HR) is mainly used to determine exercise intensity [12-14]. It is a common practice for some top professional soccer teams to systematically monitor training load with HR methods [15]. For example, the summated-heart-rate-zones method, proposed by Edwards [16], might facilitate the quantification of interval training because it divides the training session into periods spent in each of $5 \mathrm{HR}$ zones (50-60\%, 60-70\%, 70-80\%, 80-90\%, and $90-100 \%$ of maximal HR $\left.\left[\mathrm{HR}_{\max }\right]\right)$. The training duration in each zone is multiplied by different factors, which weight the higher intensity zones more than those of lower intensities. Thereafter the adjusted scores are summated.

Apart from a few top level soccer teams, the routine use of the HR-based method is not always feasible; problems include the required technical expertise, the time-consuming process of collecting HR data of all team players in each training session, and the cost of numerous HR telemetric systems. An alternative strategy to monitor training load was proposed by Foster et al. [17] and Foster [18]. Derived from the rating of perceived exertion (RPE) multiplied by session duration, this method is a simple, non-invasive technique for monitoring training load [19]. Previous research in measuring training load has shown that sessionRPE is highly correlated with HR-based assessment of training load during intermittent team sports such as soccer [15, 20,21]. It is important to note that the data found for this correlation refer to the adult category.

The individual quantification of the training load can contribute to a more accurate assessment of how the athlete is responding to the prescribed training and assist in further changes in the training program [2]. However, training that involves high intensity activities is hard to control, especially in acyclic activities like in team sports [4]. According to Casamichana and Castellano [22], it is necessary to consider a number of training load indicators to obtain additional information that would enable coaches to more accurately assess the burden imposed on players. Freitas et al. [6] suggest that physiological, psychometric, mechanical, and biochemical parameters must be used together and correlated with one another.

Some studies have examined the relationship between the results from different monitoring tools used in training sessions of the adult soccer category [22-25]. Significant correlations between some parameters have been verified; with others, however, not. To understand the relationship between the monitoring parameters is important to determine those that will be used to carry out the monitoring of the training load and improve the interpretation of the results. Wrigley et al. [26] indicate that increases in the training load intensity are related to age. The prescription and analysis of training for young soccer players should consider the specific demands in each age group [27]. In general, understanding the physical demands for each age group can provide information about the players' development profile and their levels. The training loads and the responses to these tend to be different, since they must take into account the influence of growth and maturational level [28]. Individuals of different age groups may have different responses. Thus, the relationship between the monitoring parameters may also be different.

No study has addressed the relationship between training load monitoring tools in the U-20. The tendency is that, in practice, coaches believe that the relationships are the same as those found in the adult category. Therefore, the choice of monitoring parameters and interpretation of the information they provide tend to reflect what is known about adult players. So, checking the level of association between the training load monitoring tools in the U-20 is justified for the choice and interpretation of the parameters applied depending on the specific profile of the category. In this context, the aim of the study was to analyse the responses obtained from different training load monitoring tools in the elite U-20 soccer category and check the level of association between these responses. We hypothesized that there was a very large correlation between the Edwards method and session-RPE. But there is no very large significant association between Edwards and session-RPE with all the variables that represent the high intensity activity performed by the players in training situations.

\section{Material and methods}

\section{Participants}

The participants were 10 Brazilian elite male soccer players (age, $18.61 \pm 0.95$ years; height, $176.81 \pm$ $5.03 \mathrm{~cm}$; body mass, $70.32 \pm 8.41 \mathrm{~kg}$ ) regularly involved in national competitions recognized by the Brazilian Soccer Confederation. The athletes did not present any occurrence of injuries (competitive season 2015). Enrolled were only athletes who, after medical evaluation, were eligible to participate in the routine of training and matches. 
G.S. Pinheiro, R.C. Quintao, I. Custodio, D. Casamichana, B.P. Couto, Load monitoring tools in U-20 soccer

\section{Measures}

The athletes performed a progressive test to exhaustion that assessed maximum oxygen consumption $\left(\mathrm{VO}_{2 \max }\right)$ and individual $\mathrm{HR}_{\max }[29]$. The mechanical load indicators were obtained from portable GPS devices (GPSports SPI Pro X).

These devices are currently among the most commonly used and commercially available GPS units for professional team sports. According to the manufacturer, the GPS device has a sampling frequency of $15 \mathrm{~Hz}$ and includes a $100-\mathrm{Hz}$ triaxial accelerometer. The manufacturer supplemented the GPS frequency to provide a sampling rate of $15 \mathrm{~Hz}$ [30].

Each player wore a special vest which enabled the device to be fitted to the upper part of his back. The use of the special GPS vest and the HR monitor were not intervening factors in the performance of athletes during training since the club applied this equipment in training sessions and official matches. The GPS devices were activated 15 minutes before the beginning of each training session, in accordance with the manufacturer's instructions. After recording, the data were transferred to a computer and analysed with the software package provided by the manufacturer (Software Team AMS).

The daily individual training load was calculated with the Foster's session-RPE procedure [31]. The method involved multiplying the training duration in minutes by the mean training intensity. The sessionRPE scale (Table 1) is the Borg category-ratio RPE scale (CR-10) modified by Foster et al. [31]; it translates the athlete's perception of effort into a numerical score between 0 and 10 . The test is designed to ask the athlete to respond to a simple question: 'How was your workout?' with the goal of getting an uncompli-

Table 1. CR-10 scale modified by Foster et al. [31]

\begin{tabular}{cc}
\hline Rating & Descriptor \\
\hline 0 & Rest \\
1 & Very easy \\
2 & Easy \\
3 & Moderate \\
4 & Somewhat hard \\
5 & Hard \\
6 & Very hard \\
7 & \\
8 & \\
9 & Maximal \\
10 & \\
\hline
\end{tabular}

cated answer that reflects the athlete's global impression of the workout.

All athletes had been familiarized with the scale before the start of the study (3 weeks prior to study period) and followed standardized instructions for RPE.

\section{Procedures}

A correlational descriptive design was used for the load monitoring tools: session-RPE, the HR-based method (Edwards), and mechanical load indicators obtained from portable GPS devices. The time spent in the HR zones was summated; the accumulated time in each zone (minutes) was multiplied by a factor relative (50$60 \% \mathrm{HR}_{\max }: 1 ; 60-70 \% \mathrm{HR}_{\max }: 2 ; 70-80 \% \mathrm{HR}_{\max }: 3$; $80-90 \% \mathrm{HR}_{\max }$ : 4; 90-100\% $\mathrm{HR}_{\max }$ : 5). The session-RPE was obtained by multiplying the duration of each training session (in minutes) by the intensity assigned to that session on the RPE scale. Mechanical variables acquired through the GPS devices were: total duration of the training session, total distance, average and maximum speed, distance covered in different speed zones (0-6 km/h, 6-10 km/h, 10-13 km/h, 13-16 km/h, $16-20 \mathrm{~km} / \mathrm{h},>20 \mathrm{~km} / \mathrm{h}$ ), maximum acceleration and different zones of accelerations $\left(1.0-1.5 \mathrm{~m} / \mathrm{s}^{2}, 1.5-\right.$ $2.0 \mathrm{~m} / \mathrm{s}^{2}, 2.0-2.5 \mathrm{~m} / \mathrm{s}^{2},>2.5 \mathrm{~m} / \mathrm{s}^{2}$ ), number of accelerations in different zones per minute $\left(1.0-1.5 \mathrm{~m} / \mathrm{s}^{2}\right.$, $\left.1.5-2.0 \mathrm{~m} / \mathrm{s}^{2}, 2.0-2.5 \mathrm{~m} / \mathrm{s}^{2},>2.5 \mathrm{~m} / \mathrm{s}^{2}\right)$.

The total of 15 training sessions were monitored between March and April in the 2015 competitive season. The monitored training sessions occurred in the morning (between 9:00 am and 11:00 am, on Monday to Friday), with an interval of 24 hours between them, and were all performed on the same fields with natural grass. The mean temperature was $28.3^{\circ} \mathrm{C} \pm 3.03^{\circ} \mathrm{C}$ and the mean relative humidity was $59.36 \% \pm 9.69 \%$, as recorded by a thermometer (Big Digit Hygro-Thermometer, Extech Instruments).

All the training sessions started with a warm-up (15-30 minutes), containing preparatory activities such as stretching, low intensity running and small-sided games. After this period, technical tactical activities were carried out. During the rest periods, players were allowed to drink liquids ad libitum. It is noteworthy that the players were advised to keep their normal diet. During the study period, the athletes performed 2-3 strength training sessions per week. These sessions took place in the gym under the supervision of the club.

The mean duration of the sessions monitored was $93.0 \pm 17.23$ minutes. During these sessions, the athletes covered an average distance of 6049.4 meters, at a maximum average speed of $28.4 \mathrm{~km} / \mathrm{h}$ and an average 
speed of $4.0 \mathrm{~km} / \mathrm{h}$, with $\mathrm{HR}_{\max }$ of $187.4 \mathrm{bpm}(100.64 \%$ of the $\mathrm{HR}_{\max }$ achieved in the test laboratory) and an average HR during training of $138.2 \mathrm{bpm}(74.22 \%$ of the $\mathrm{HR}_{\max }$ achieved in the test laboratory).

In order ensure the ecological validity of the data collected, the researchers did not make any interference in the training sessions, which were planned and executed by the club staff. Data analysis included all activities performed during the training sessions, together with the recovery periods [23].

\section{Statistical analysis}

Descriptive statistics were calculated for all variables and reported as means and standard deviations. The normality of the data was verified by the KolmogorovSmirnov test. The homogeneity of variances was examined with the Levene's test. The association between variables was determined with the use of the Pearson correlation coefficients, intra-individual. The magnitude of correlation coefficients was considered as trivial $(r<0.1)$, small $(0.1 \leq r<0.3)$ moderate $(0.3 \leq r<0.5)$, large $(0.5 \leq r<0.7)$, very large $(0.7 \leq r<0.9)$, almost perfect $(0.9 \leq r<1)$ and perfect $(r=1)$ [32]. All statistical analyses were performed with the SPSS 20.0 software for Windows, with significance set at $p<0.05$.

\section{Ethical approval}

The research related to human use has been complied with all standards set by the Brazilian National Council of Health (Res. 466/12) involving human research, has followed the tenets of the Declaration of Helsinki, and has been approved by the Research Ethics Committee (COEP) of the Federal University of Minas Gerais. In addition, an authorization letter was obtained from the club, agreeing with the whole procedure.

\section{Informed consent}

Informed consent has been obtained from all individuals included in this study.

\section{Results}

The mean value for session-RPE (arbitrary units, AU) during the sessions monitored was $287.83 \pm 106.72 \mathrm{AU}$. The mean value for the training impulse (TRIMP) Edwards (AU) during the sessions monitored was 251.79 $\pm 91.13 \mathrm{AU}$. A significant large correlation was found for the results of session-RPE with TRIMP-Edwards $(r=0.564, p<0.05)$, with total distance covered $(r=$ $0.446, p<0.01$ ), with the distance covered at $0-6 \mathrm{~km} / \mathrm{h}$ $(r=0.399, p<0.01), 6-10 \mathrm{~km} / \mathrm{h}(r=0.344, p<0.01)$,
Table 2. General correlations between all variables

\begin{tabular}{lcc} 
& $\begin{array}{c}\text { Session- } \\
\text { RPE }\end{array}$ & TRIMP \\
\hline Session-RPE & - & $0.564^{*}$ \\
TRIMP & $0.564^{*}$ & - \\
Total distance covered & $0.446^{* *}$ & $0.642^{* *}$ \\
Average speed & -0.161 & 0.158 \\
Average heart rate & -0.187 & $0.333^{* *}$ \\
Distance covered at $0-6 \mathrm{~km} / \mathrm{h}$ & $0.399^{* *}$ & $0.634^{* *}$ \\
Distance covered at $6-10 \mathrm{~km} / \mathrm{h}$ & $0.344^{* *}$ & $0.568^{* *}$ \\
Distance covered at $10-13 \mathrm{~km} / \mathrm{h}$ & $0.307^{* *}$ & $0.424^{* *}$ \\
Distance covered at $13-16 \mathrm{~km} / \mathrm{h}$ & $0.325^{* *}$ & $0.289^{* *}$ \\
Distance covered at $16-20 \mathrm{~km} / \mathrm{h}$ & $0.386^{* *}$ & $0.201^{*}$ \\
Distance covered at $>20 \mathrm{~km} / \mathrm{h}$ & 0.006 & 0.014 \\
Number of accelerations $1.0-1.5 \mathrm{~m} / \mathrm{s}^{2}$ & -0.194 & -0.194 \\
Number of accelerations $1.5-2.0 \mathrm{~m} / \mathrm{s}^{2}$ & -0.178 & -0.178 \\
Number of accelerations $2.0-2.5 \mathrm{~m} / \mathrm{s}^{2}$ & -0.171 & -0.171 \\
Number of accelerations $>2.5 \mathrm{~m} / \mathrm{s}^{2}$ & -0.236 & -0.236 \\
Normalized acceleration $1.0-1.5 \mathrm{~m} / \mathrm{s}^{2}$ & -0.118 & -0.118 \\
Normalized acceleration $1.5-2.0 \mathrm{~m} / \mathrm{s}^{2}$ & -0.038 & -0.038 \\
Normalized acceleration $2.0-2.5 \mathrm{~m} / \mathrm{s}^{2}$ & -0.058 & -0.058 \\
Normalized acceleration $>2.5 \mathrm{~m} / \mathrm{s}^{2}$ & -0.035 & -0.035 \\
\hline
\end{tabular}

RPE - rating of perceived exertion, TRIMP - training impulse ${ }^{*}$ significant correlation at $0.05 ;{ }^{* *}$ significant correlation at 0.01

$10-13 \mathrm{~km} / \mathrm{h}(r=0.307, p<0.01), 13-16 \mathrm{~km} / \mathrm{h}(r=0.325$, $p<0.01)$, and $16-20 \mathrm{~km} / \mathrm{h}(r=0.386, p<0.01)$.

No significant correlations were observed between session-RPE and mean speed, mean HR of the training session, distance covered at $>20 \mathrm{~km} / \mathrm{h}$, number of accelerations performed in different tracks, number of normalized accelerations, or distance covered per minute (Table 2).

The TRIMP-Edwards showed significant large correlations with the total distance covered $(r=0.642$, $p<0.01)$, mean HR $(r=0.333, p<0.01)$, distances at $0-6 \mathrm{~km} / \mathrm{h}(r=0.634, p<0.01), 6-10 \mathrm{~km} / \mathrm{h}(r=0.568$, $p<0.01), 10-13 \mathrm{~km} / \mathrm{h}(r=0.424, p<0.01), 13-16 \mathrm{~km} / \mathrm{h}$ $(r=0.289, p<0.01)$, and $16-20 \mathrm{~km} / \mathrm{h}(r=0.201, p<$ $0.01)$. There were no significant correlations between the TRIMP-Edwards and mean speed, distance covered at $>20 \mathrm{~km} / \mathrm{h}$, number of accelerations performed on different tracks, or number of accelerations per minute.

\section{Discussion}

This study analysed the responses from different training load monitoring tools in the elite U-20 soccer category and examined the level of association between these responses. The hypothesis that the TRIMP-Edwards method and session-RPE present a very large correlation was not confirmed in the study. 
G.S. Pinheiro, R.C. Quintao, I. Custodio, D. Casamichana, B.P. Couto, Load monitoring tools in U-20 soccer

These results demonstrate that the association between the TRIMP-Edwards and session-RPE is similar to the correlation found in the literature [23] for the adult soccer category $(r=0.57)$. The main finding of this study was that the results of monitoring training load by session-RPE and the TRIMP-Edwards method showed trivial correlation with the main variables that represented the high intensity activity performed by the players in training situations.

Impellizzeri et al. [15] used the session-RPE to quantify training load in soccer and examined the correlations with other methods, based on HR response to exercise. These authors found individual correlations $(r, 0.54-0.78)$ statistically significant ( $p$ $<0.01$ ) between the session-RPE and TRIMP-Edwards. The correlation values observed in their study were similar to the findings in the present study ( $r=$ $0.564, p<0.01$ ) and slightly lower than those reported by prior investigators [18]. One possible explanation for the lower correlations could be the increased anaerobic contribution to energy supply during soccer training sessions [15]. This may indicate a limitation of this instrument, since it does not reflect the intensity of activities with short duration and high intensity [33, 34]. Many soccer analysis studies have shown that this sport requires repeated maximum actions with short duration and incomplete recovery interval [35]. Therefore, these actions are not monitored properly by TRIMP-Edwards because HR is a limited parameter to control this type of activity. The failure of this method to monitor situations with short duration and high intensity may compromise the monitoring of moments usually more decisive in soccer.

The TRIMP-Edwards, parameter commonly applied in soccer, uses the individual response of HR training session to estimate the athlete's response to this training load. Despite its popularity, the method has not proved valid in soccer. Its strategy for accounting the differences in exercise considers a linearity of HR responses; however, the responses are not linear [36]. Some limitations of methods based on $\mathrm{HR}$ responses have been reported in the literature [2, 15, 37], especially regarding the monitoring of training loads that involve intermittent high intensity activities, such as soccer.

The results of this study show that identical training loads can cause different responses in athletes with different individual characteristics (chronological age, sports experience, aerobic capacity, among others). The training stimulus may be suitable for an athlete, but inappropriate for another [38]. The HR- based method (Edwards) may not represent the actual demands in a practice situation since it is based on a linear HR and takes into account the duration of the training session including rest times. Besides, HR response is slow for high-intensity actions, so this method is a limited tool to monitor the training load responses and indicate the reality of these situations in sports.

These findings can be explained with the fact that sports actions involve rapid accelerations, decelerations, and non-linearity, therefore the HR responses may have different time. The monitoring of accelerations seems to have great importance in identifying energy expenditure and level of neuromuscular fatigue in soccer players since the accelerations can provide an instant report of mechanical stress [39]. Casamichana et al. [23] report the importance of monitoring through the use of accelerations. The magnitude of the accelerations and decelerations can therefore be associated with the physiological impact suffered by athletes. In the present study, the TRIMPEdwards and session-RPE showed no significant correlation with the number of accelerations in different intensity ranges. When monitoring the response to training loads in players, it is important to consider such aspects as acceleration because accelerations are more common in small areas, e.g. those used in small-sided games in training sessions [23]. Therefore, the failure of monitoring accelerations may underestimate the players' engagement in high intensity activities [40]. Perhaps using different TRIMP by thresholds will allow to find different results.

The differences between the levels of correlation between training load monitoring tools obtained in this study for the U-20 and in the literature for the adult category suggest that the relation between the monitoring parameters may change depending on the age group. Mujika et al. [41] suggest that improvements in performance across the age groups are probably related to the influence of aging on stress during maximum exercise, and differences in height and weight in the age groups. Harley et al. [27] claim that owing to variations in performance characteristics between age groups in youth, performance measures should be considered in relation to the performance characteristics of particular age groups. These authors suggest that the prescription of training for youth soccer players should involve the specific demands for each age group and the maturation performance capacity indicator. Besides that, in this study, the low correlation values found may be due to 
the fact that the monitoring tools were used to evaluate different parameters, which demonstrates the importance of multi-parameter monitoring.

Some studies found that physical performance during the match changed throughout the season [42] and was related to the level of players' training [43]. Therefore, a major limitation of this study was that it did not examine the correlation between the training load monitoring tools at different times of the season; this factor could influence the training load and change the relationships between load indicators. It is suggested that future studies should compare responses obtained from different monitoring tools with regard to different categories.

\section{Conclusions}

The results of training load monitoring through session-RPE and HR-based method (Edwards) do not present very large correlations with a number of mechanical variables obtained from the GPS devices in the elite U-20 soccer players. These variables represented the high intensity activities performed by the players in training situations. The TRIMP-Edwards and session-RPE are limited tools of monitoring training load responses to indicate the reality of training situations (high-intensity action, with recovery intervals). Akubat et al. [44] suggest that the use of an integrated list of monitoring parameters may be more useful in the sports scene than a single tool. There is no monitoring approach universally adopted in top-level soccer [45].

The differences in validity and interunit reliability between different GPS units for measuring athlete movement demands require inspection, and it is important for coaches and conditioning staff to understand the operation of their chosen devices.

\section{Acknowledgements}

We thank the Coordenação de Aperfeiçoamento de Pessoal de Nível Superior (CAPES) and Clube Atlético Mineiro (CAM-MG). We are also grateful to the University of the Basque Country (UPV-EHU) and the Department of Physical Education and Sport. Funding disclosure: CAPES.

\section{Disclosure statement}

No author has any financial interest or received any financial benefit from this research.

\section{Conflict of interest}

The authors state no conflict of interest.

\section{References}

1. Szmuchrowski LA, Claudino JGO, Albuquerque Neto SL, Menzel HJK, Couto BP. Determination of the minimum number of vertical jumps to monitor the responses to plyometric training [in Portuguese]. Motricidade. 2012; 8(S2):383-392.

2. Borresen J, Lambert MI. Quantifying training load: a comparison of subjective and objective methods. Int $\mathrm{J}$ Sports Physiol Perform. 2008;3(1):16-30; doi: 10.1123/ ijspp.3.1.16.

3. Meeusen R, Duclos M, Gleeson M, Rietjens G, Steinacker JM, Urhausen A. Prevention, diagnosis, and treatment of the overtraining syndrome - ECSS position statement 'task force'. Eur J Sport Sci. 2006;6(1):1-14; doi: 10.1080/17461390600617717.

4. Brink MS, Nederhof E, Visscher C, Schmikli SL, Lemmink KA. Monitoring load, recovery, and performance in young elite soccer players. J Strength Cond Res. 2010; 24(3):597-603; doi: 10.1519/JSC.0b013e3181c4d38b.

5. Coutts AJ, Wallace LK, Slattery KM. Monitoring changes in performance, physiology, biochemistry, and psychology during overreaching and recovery in triathletes. Int J Sports Med. 2007;28(2):125-134; doi: 10.1055/ s-2006-924146.

6. Freitas DS, Miranda R, Bara Filho M. Psychological, physiological and biochemical markers of the training load and the overtraining effects [in Portuguese]. Rev Bras Cineantropom DesempenhoHum.2009;11(4):457465; doi: 10.5007/1980-0037.2009v11n4p457.

7. Robson-Ansley PJ, Gleeson M, Ansley L. Fatigue management in the preparation of Olympic athletes. J Sports Sci. 2009;27(13):1409-1420; doi: 10.1080/02640410 802702186.

8. Stølen T, Chamari K, Castagna C, Wisløff U. Physiology of soccer: an update. Sports Med. 2005;35(6):501-536; doi: 10.2165/00007256-200535060-00004.

9. Flanagan T, Merrick E. Quantifying the work-load of soccer players. In: Spinks W, Reilly T, Murphy A (eds.), Science and football IV. London, New York: Routledge; 2002; 341-349.

10. Céline CG, Monnier-Benoit P, Groslambert A, Tordi N, Perrey S, Rouillon JD. The perceived exertion to regulate a training program in young women. J Strength Cond Res. 2011;25(1):220-224; doi: 10.1519/JSC.0b013e318 1 aff3a6.

11. Gabbett TJ. The development and application of an injury prediction model for noncontact, soft-tissue injuries in elite collision sport athletes. J Strength Cond Res. 2010; 24(10):2593-2603; doi: 10.1519/JSC.0b013e3181f19da4.

12. Bangsbo J. The physiology of soccer: with special reference to intense intermittent exercise. Acta Physiol Scand. 1994;619(Suppl):1-155.

13. Helgerud J, Engen LC, Wisløff U, Hoff J. Aerobic endurance training improves soccer performance. Med Sci Sports Exerc. 2001;33(11):1925-1931; doi: 10.1097/ 00005768-200111000-00019. 
G.S. Pinheiro, R.C. Quintao, I. Custodio, D. Casamichana, B.P. Couto, Load monitoring tools in U-20 soccer

14. Hoff J, Wisløff U, Engen LC, Kemi OJ, Helgerud J. Soccer specific aerobic endurance training. Br J Sports Med. 2002;36(3):218-221; doi: 10.1136/bjsm.36.3.218.

15. Impellizzeri FM, Rampinini E, Coutts AJ, Sassi A, Marcora SM. Use of RPE-based training load in soccer. Med Sci Sports Exerc. 2004;36(6):1042-1047; doi: 10.1249/ 01.MSS.0000128199.23901.2F.

16. Edwards S. High performance training and racing. In: Edwards S (ed.), Heart rate monitor book. Sacramento: Feet Fleet Press; 1993; 113-123.

17. Foster C, Hector LL, Welsh R, Schrager M, Green MA, Snyder AC. Effects of specific versus cross-training on running performance. Eur J Appl Physiol Occup Physiol. 1995;70(4):367-372; doi: 10.1007/BF00865035.

18. Foster C. Monitoring training in athletes with reference to overtraining syndrome. Med Sci Sports Exerc. 1998; 30(7):1164-1168; doi: 10.1097/00005768-199807000 $-00023$.

19. Gomez-Piriz PT, Jiménez-Reyes P, Ruiz-Ruiz C. Relation between total body load and session rating of perceived exertion in professional soccer players. J Strength Cond Res. 2011;25(8):2100-2103; doi: 10.1519/JSC.0b013 e3181fb4587.

20. Lovell TWJ, Sirotic AC, Impellizzeri FM, Coutts AJ. Factors affecting perception of effort (session rating of perceived exertion) during rugby league training. Int $\mathrm{J}$ Sports Physiol Perform. 2013;8(1):62-69; doi: 10.1123/ ijspp.8.1.62.

21. Coutts AJ, Rampinini E, Marcora SM, Castagna C, Impellizzeri FM. Heart rate and blood lactate correlates of perceived exertion during small-sided soccer games. J Sci Med Sport. 2009;12(1):79-84; doi: 10.1016/j.jsams. 2007.08.005.

22. Casamichana D, Castellano J. The relationship between intensity indicators in small-sided soccer games. J Hum Kinet. 2015;46(1):119-128; doi: 10.1515/hukin-2015 -0040 .

23. Casamichana D, Castellano J, Calleja-Gonzalez J, San Román J, Castagna C. Relationship between indicators of training load in soccer players. $J$ Strength Cond Res. 2013;27(2):369-374; doi:10.1519/JSC.0b013e3182548af1.

24. Scott TJ, Black CR, Quinn J, Coutts AJ. Validity and reliability of the session-RPE method for quantifying training in Australian football: a comparison of the CR10 and CR100 scales. J Strength Cond Res. 2013;27(1): 270-276; doi: 10.1519/JSC.0b013e3182541d2e.

25. Gallo T, Cormack S, Gabbett T, Williams M, Lorenzen $\mathrm{C}$. Characteristics impacting on session rating of perceived exertion training load in Australian footballers. J Sports Sci. 2015;33(5):467-475; doi: 10.1080/0264 0414.2014.947311.

26. Wrigley R, Drust B, Stratton G, Scott M, Gregson W. Quantification of the typical weekly in-season training load in elite junior soccer players. J Sports Sci. 2012; 30(15):1573-1580; doi: 10.1080/02640414.2012.709265.

27. Harley JA, Barnes CA, Portas M, Lovell R, Barrett S, Paul D, et al. Motion analysis of match-play in elite U12 to U16 age-group soccer players. J Sports Sci. 2010; 28(13):1391-1397; doi:10.1080/02640414.2010.510142.

28. Paul DJ, Nassis GP. Physical fitness testing in youth soccer: issues and considerations regarding reliability, validity and sensitivity. Pediatr Exerc Sci. 2015;27(3): 301-313; doi: 10.1123/mc.2014-0085.

29. Dittrich N, da Silva JF, Castagna C, de Lucas RD, Guglielmo LG. Validity of Carminatti's test to determine physiological indices of aerobic power and capacity in soccer and futsal players. J Strength Cond Res. 2011; 25(11):3099-3106;doi:10.1519/JSC.0b013e3182132ce7.

30. Aughey RJ, Falloon C. Real-time versus post-game GPS data in team sports. J Sci Med Sport. 2010;13(3):348349; doi: 10.1016/j.jsams.2009.01.006.

31. Foster C, Florhaug JA, Franklin J, Gottschall L, Hrovatin LA, Parker S, et al. A new approach to monitoring exercise training. $J$ Strength Cond Res. 2001;15(1): 109-115; doi: 10.1519/00124278-200102000-00019.

32. Hopkins WG. A scale of magnitudes for effect statistics. 2002. Available from: http://www.sportsci.org/resource/ stats/effectmag.html.

33. Banister EW. Modeling elite athletic performance. In: MacDougall JD, Wenger HA, Green HJ (eds.), Physiological testing of elite athletes. Champaign: Human Kinetics; 1991; 403-424.

34. Stagno KM, Thatcher R, Van Someren KA. A modified TRIMP to quantify the in-season training load of team sport players. J Sports Sci. 2007;25(6):629-634; doi: 10.1080/02640410600811817.

35. Spencer M, Bishop D, Dawson B, Goodman C. Physiological and metabolic responses of repeated-sprint activities: specific to field-based team sports. Sports Med. 2005;35(12):1025-1044; doi: 10.2165/00007256-2005 35120-00003.

36. Manzi V, Iellamo F, Impellizeri F, D’Ottavio S, Castagna $C$. Relation between individualized training impulses and performance in distance runners. Med Sci Sports Exerc. 2009;41(11):2090-2096; doi: 10.1249/ MSS.0b013e3181a6a959.

37. Alexiou H, Coutts AJ. A comparison of methods used for quantifying internal training load in women soccer players. Int J Sports Physiol Perform. 2008;3(3):320330; doi: 10.1123/ijspp.3.3.320.

38. Gabbett TJ. The training-injury prevention paradox: should athletes be training smarter and harder? $\mathrm{Br} \mathrm{J}$ Sports Med. 2016;50(5):273-280; doi: 10.1136/bjsports-2015-095788.

39. Osgnach C, Poser S, Bernardini R, Rinaldo R, di Prampero PE. Energy cost and metabolic power in elite soccer: a new match analysis approach. Med Sci Sports Exerc. 2010;42(1):170-178; doi:10.1249/MSS.0b013e3181ae5cfd.

40. Varley MC, Aughey RJ. Acceleration profiles in elite Australian soccer. Int J Sports Med. 2013;34(1):34-39; doi: 10.1055/s-0032-1316315.

41. Mujika I, Spencer M, Santisteban J, Goiriena JJ, Bishop D. Age-related differences in repeated-sprint ability in highly trained youth football players. J Sports Sci. 
2009;27(14):1581-1590; doi: 10.1080/026404109033 50281.

42. Mohr M, Krustrup P, Bangsbo J. Match performance of high-standard soccer players with special reference to development offatigue. J Sports Sci.2003;21(7):519528; doi: 10.1080/0264041031000071182.

43. Rampinini E, Coutts AJ, Castagna C, Sassi R, Impellizzeri FM. Variation in top level soccer match performance. Int J Sports Med. 2007;28(12):1018-1024; doi: 10.1055/s-2007-965158.

44. Akubat I, Barrett S, Abt G. Integrating the internal and external training loads in soccer. Int J Sports Physiol Perform. 2014;9(3):457-462; doi: 10.1123/ijspp.2012-0347.

45. Akenhead R, Nassis GP. Training load and player monitoring in high-level football: current practice and perceptions. Int J Sports Physiol Perform. 2015;11(5):587593; doi: 10.1123/ijspp.2015-0331. 